\title{
A IMPORTÂNCIA DO PROCESSO ELEITORAL E AS PROPOSTAS DE GESTÃo DO CBC
}

\author{
THE IMPORTANCE OF THE ELECTORAL PROCESS AND THE PROPOSALS FOR \\ ADMINISTRATION OF THE CBC
}

\author{
TCBCEdmundo Machado Ferraz \\ Presidente Colégio Brasileiro de Cirurgiões
}

Pela quarta vez em sua historia o Colégio Brasileiro de Cirurgiões escolheu por eleição direta o seu Diretório Nacional.

Em 27 de agosto de 1929, 58 cirurgiões do Rio de Janeiro, liderados por Antonio Benevides Barbosa Vianna aprovaram o primeiro Estatuto e fundaram o Colégio Brasileiro de Cirurgiões, que evoluiu para cerca de 6.000 membros, tornando-se a maior entidade cirúrgica da América Latina e a segunda ou terceira do mundo (disputando com o Japão).

Localizada no Rio, expandiu-se para São Paulo e para todo o Brasil atingindo através dos Capítulos a dimensão continental de nosso país.

Contudo, por representarem cerca de $50 \%$ dos votos que decidiam o processo eleitoral (membros Titulares e Eméritos), Rio de Janeiro e São Paulo lideraram a composição do Diretório Nacional ao longo dos anos da história do Colégio Brasileiro de Cirurgiões.

No processo eleitoral de 2007, registraram-se pela primeira vez, duas chapas lideradas por candidatos fora do eixo Rio - São Paulo.

A eleição processou-se coordenada por um Colégio Eleitoral de alto nível composto por Ex-Presidentes do CBC, transcorrendo o processo democrático de forma transparente até a apuração final em 27/11/07.

Concluindo o processo eleitoral, a nossa Instituição, o Colégio Brasileiro de Cirurgiões emergiu como o grande vencedor do embate enaltecido pela lisura e dignidade como se processou a disputa, legitimando a nossa Instituição e o Diretório Nacional eleito para gestão 2008-2009.

A necessidade de integração nacional, a educação continuada, a ênfase na formação e proteção profissional do cirurgião geral e a integração do $\mathrm{CBC}$ com as diferentes sociedades cirúrgicas brasileiras são os objetivos atuais do CBC..
Em nosso discurso de posse no dia 11/01/08 reiteramos nosso compromisso com a tradição e a capacidade demonstrada ao longo de 78 anos do Colégio Brasileiro de Cirurgiões de atualizar-se e adaptar-se as transformações oriundas do conhecimento e da necessidade e demandas da sociedade brasileira.

Vivemos uma época de exigências crescentes agravadas por um cenário de grandes dificuldades do setor público, péssimo financiamento do sistema único de saúde responsável pelo atendimento de cerca de 140 milhões de brasileiros, agravado pela pressão exercida pela sociedade e pelos planos de saúde sobre o trabalho médico mal remunerado e em péssimas condições de trabalho, com crescentes demandas judiciais, necessitando ainda o cirurgião geral brasileiro de não só melhorar as suas condições de exercício profissional como também de educação continuada, particularmente em áreas remotas, distante dos grandes centros urbanos, com o objetivo de melhor atendimento de nossa população.

Esse é o tamanho de nosso desafio.

Vamos enfrentá-lo conhecendo os anseios e expectativas de desempenho de nossa gestão, modernizando e adaptando mais ainda a capacidade de resposta de nossa instituição, o Colégio Brasileiro de Cirurgiões.

Mas não pretendemos fazer isso sozinho.

Estamos lançando uma Enquete Nacional dirigida a todos os membros do CBC e não apenas aos votantes (Titulares e Eméritos).

Desejamos a opinião e a participação de todos, pois não pretendemos dirigir o Colégio apenas com as nossas idéias: desejando conhecer o pensamento dominante em nossa entidade.

Vamos portanto, todos juntos, contribuir para uma gestão representativa da vontade do cirurgião brasileiro. 